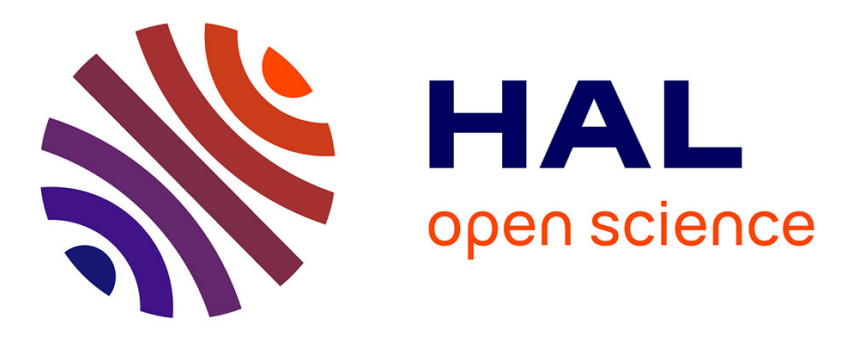

\title{
Q fever epidemic in Cayenne, French Guiana, epidemiologically linked to three-toed sloth
}

\author{
Vincent Pommier De Santi, Sebastien Briolant, Aba Mahamat, Carole \\ Ilcinkas, Denis Blanchet, Benoit De Thoisy, Yann Reynaud, Georges Hyvert, \\ Jean-Lou Marie, Sophie Edouard, et al.
}

\section{To cite this version:}

Vincent Pommier De Santi, Sebastien Briolant, Aba Mahamat, Carole Ilcinkas, Denis Blanchet, et al.. Q fever epidemic in Cayenne, French Guiana, epidemiologically linked to three-toed sloth. Comparative Immunology, Microbiology and Infectious Diseases, 2018, 56, pp.34-38. 10.1016/j.cimid.2017.12.004 . hal-01780643

\section{HAL Id: hal-01780643 https://hal.science/hal-01780643}

Submitted on 10 Apr 2019

HAL is a multi-disciplinary open access archive for the deposit and dissemination of scientific research documents, whether they are published or not. The documents may come from teaching and research institutions in France or abroad, or from public or private research centers.
L'archive ouverte pluridisciplinaire HAL, est destinée au dépôt et à la diffusion de documents scientifiques de niveau recherche, publiés ou non, émanant des établissements d'enseignement et de recherche français ou étrangers, des laboratoires publics ou privés. 


\title{
Q fever epidemic in Cayenne, French Guiana, epidemiologically linked to three-toed sloth
}

\author{
Vincent Pommier de Santi ${ }^{\mathrm{a}, \mathrm{b}, *}$, Sébastien Briolant ${ }^{\mathrm{b}, \mathrm{c}, \mathrm{d}}$, Aba Mahamat ${ }^{\mathrm{e}}$, Carole Ilcinkas ${ }^{\mathrm{f}}$, \\ Denis Blanchet $^{\mathrm{e}}$, Benoit de Thoisy ${ }^{\mathrm{d}}$, Yann Reynaud ${ }^{\mathrm{d}}$, Georges Hyvert ${ }^{\mathrm{f}}$, Jean-Lou Marié ${ }^{\mathrm{g}, \mathrm{h}}$, \\ Sophie Edouard ${ }^{\mathrm{i}}$, Bernard Davoust ${ }^{\mathrm{i}}$, Didier Raoult ${ }^{\mathrm{i}}$
}

${ }^{a}$ Military Center for Epidemiology and Public health, CESPA, Marseille, France

${ }^{\mathrm{b}}$ Aix Marseille Univ, IRD, AP-HM, SSA, VITROME, IHU-Méditerranée Infection, Marseille, France

${ }^{\mathrm{c}}$ Institut de Recherche Biomédicale des Armées, Brétigny-sur-Orge, France

d Institut Pasteur, Cayenne, French Guiana, France

e Andrée Rosemon Hospital, Cayenne, French Guiana, France

${ }_{\mathrm{f}}^{\mathrm{f}}$ Direction Interarmées du Service de Santé en Guyane, Cayenne, French Guiana, France

${ }^{\mathrm{g}}$ French Forces Medical Service Working Group on Animal Epidemiology, DRSSA Toulon, France

${ }^{\mathbf{h}}$ French Military Health Service Academy - École du Val-de-Grâce, Paris, France

${ }^{\mathrm{i}}$ Aix-Marseille Université, URMITE, Marseille, France

\section{A R T I C L E I N F O}

\section{Keywords:}

$\mathrm{Q}$ fever

Coxiella burnetii

Military

Outbreak

Epidemic

French Guiana

Epidemiology

Sloth

\begin{abstract}
A B S T R A C T
A Q fever epidemic occurred in 2013 in a small military residential area in Cayenne, French Guiana. A retrospective cohort study was conducted to identify $\mathrm{Q}$ fever risk factors. Confirmed acute $\mathrm{Q}$ fever case was defined as positive serology (IgM $\geq 50$ and phase II IgG $\geq 200$ ) and/or positive qPCR on serum or blood. In addition, wild mammals were captured at the study site and tested by serology and real-time PCR performed on blood, vaginal swabs and ticks. The attack rate was 20 percent (11/54). All the cases were symptomatic with fever $>38.5^{\circ} \mathrm{C}$ and community-acquired pneumonia for four cases. Log binomial multivariate models identified two independent risk factors associated with $Q$ fever: to clean the house (RRa $=7.5 \mathrm{CI} 95 \%$ [1.03-55.3]) and to carry a three-toed sloth in arms ( $\mathrm{RRa}=2.6 \mathrm{CI} 95 \%$ [1.1-5.8]). Eighteen marsupial individuals were captured, all PCRs were negative but $17 \%(3 / 18)$ had a positive serology. Another study conducted after the epidemic found only one (1/4) three-tooth sloth (Bradypus tridactylus) with feces highly infectious for C. burnetii MST17. The same strain $C$. burnetii genotype 17 has been laboratory- confirmed in this mammal and in human cases. These results support the implication of three-toed-sloth in this epidemic. Human contamination mainly occurs through inhalation of infectious aerosols as suggested by high relative risk associated with house cleaning activities and pulmonary forms of the disease, and through direct contact with three- toed-sloth. Positive serological results among marsupials confirm wildlife exposure and suggest a more complex sylvatic transmission cycle among wild mammals.
\end{abstract}

\section{Introduction}

Q fever, a cosmopolitan zoonosis caused by the intracellular bacterium Coxiella burnetii, is a public health concern in Cayenne, the main city of French Guiana, a French overseas entity located on the northeast coast of South America [1,2]. In a prospective study conducted from 1996 to 2000, the mean annual incidence rate was estimated to 37 cases per 100,000 inhabitants, one of the highest in the world [3]. Pneumonia is the primary manifestation of acute $\mathrm{Q}$ fever, representing $24.4 \%$ of the community-acquired pneumonia admitted to the Cayenne regional hospital [4]. A unique genotype, $C$. burnetii multispacer sequence type MST17, only isolated from Cayenne to date, is responsible for the disease [5]. Several risk factors have been identified such as living near forested areas and practicing activities resulting in inhalation of aerosols of dusts [3]. In contrast, no link with classical sources of C. burnetii (cattle, sheep, or goat birth products) has been ever identified and a wild reservoir has been suspected [2,3,6,7].

The "Camp du Tigre" is a military training camp in the city of Cayenne with a residential area of 18 houses, surrounded by rainforest and located at the top of a hill (Fig. 1). The Camp du Tigre has been

\footnotetext{
* corresponding author.

E-mail address: pommierdesantiv@imtssa.fr (V. Pommier de Santi).
} 


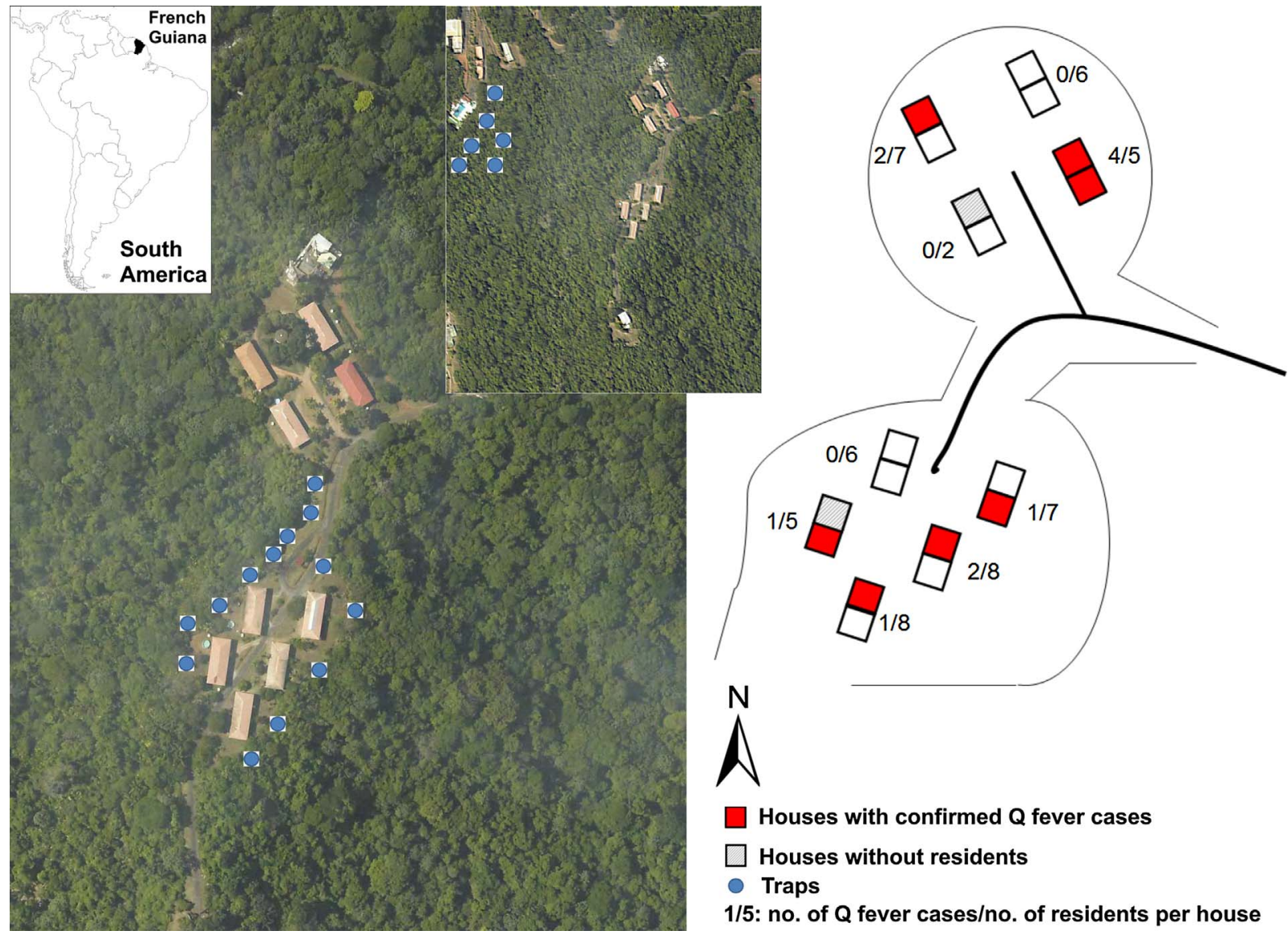

Fig. 1. Camp du Tigre military residential area $-\mathrm{Q}$ fever cases distribution in houses. Aerial photography by French armed forces in French Guiana.

specifically identified in a previous study as an area with high $\mathrm{Q}$ fever incidence rate, with several cases occurring among military personnel during 1996-2000 [3,8]. In 2004-2005, a Q fever outbreak occurred among military personnel living at the residential area, resulting in a total of $10 \mathrm{Q}$ fever cases (unpublished data). In March 2013, once again one confirmed and two suspected $Q$ fever cases occurred in this population. A study conducted after the outbreak among sheep, goats, wild mammals and birds living on and around the hill found only one (1/4) three-tooth sloth (Bradypus tridactylus) with feces highly infectious for C. burnetii MST17 and $88 \%$ of his ticks were positives for $C$. burnetii using specific PCR [6]. But a link with human cases was not confirmed. We report the results of the investigations conducted during this outbreak.

\section{Material and methods}

\subsection{Epidemiological investigation}

Fifty-four inhabitants (20 active military personnel and 34 members of their families) were living in this residential area (Fig. 1). Considering the frequency of asymptomatic $Q$ fever infections and the risk of chronic $Q$ fever, a serological screening based on two samples at least 3 weeks apart, was first systematically proposed to all the inhabitants. In addition, the population was followed up during three months and Q fever diagnosis was systemically performed to any new patient presenting a fever episode $\left(\mathrm{T}^{\circ} \geq 38.5^{\circ} \mathrm{C}\right)$ by indirect immunofluorescence assay serology, one sample taken the first week of illness and a second 3 weeks later. Quantitative real-time polymerase chain reaction (qPCR) targeting the IS1111 sequence on serum and blood samples was also performed as described before [9]. We used lyophilization to concentrate DNA and increase qPCR sensitivity [10]. Then, we genotyped
C. burnetii positive DNA using a specific qPCR for C. burnetii MST17 [11]. Any new Q fever case was treated with $200 \mathrm{mg}$ of doxycycline daily during three weeks [4]. Patients were follow-up after treatment, with repeated serology every 6-months. Retrospective cohort study was conducted to identify $\mathrm{Q}$ fever risk factors during this outbreak. All the 54 inhabitants were included with their consents in the study and completed a questionnaire containing information on occupation, housing and contacts with animals during the month preceding first serology or the month preceding symptoms for patients with confirmed $Q$ fever. The parents answered for their youngest children. Confirmed acute $Q$ fever case was defined as positive serology ( $\operatorname{IgM} \geq 50$ and phase II IgG $\geq 200$ ) and/or positive qPCR on serum or blood [12]. Elevated phase I IgG titer $(\geq 1: 800)$ was in favor of persistent focalized $\mathrm{Q}$ fever infection and the presence of low phase I and II IgG titer $(\leq 1: 400)$ without IgM considered as past infection.

\subsection{Investigation in wild mammals}

As the reservoir of $C$. burnetii is still unknown in French Guiana, we could not speculate on which mammal species (and parturition period) to target. Wild mammals were captured at the study site, up and down the hill, between the 18th and the 23rd of May 2013, using BTTm (BTTm, Besançon Trap Service mécanique, France), Tomahawk (Tomahawk Live Trap Co., Tomahawk, WI) and Sherman traps (Sherman Trap Co., Tallahassee, FL) for a total effort of 138 trap/nights (Fig. 1, Fig. 2). A total of 18 individuals' males and females belonging to two marsupial species were captured: 12 Didelphis marsupialis and 6 Philander opossum. Whenever possible, blood samples were collected $(n=18)$, vaginal swab $(n=14)$ as well as ticks when present $(n=15)$. C. burnetii replicates to very high levels in the placental tissue of infected animals compare to waste products as feces or urine [13]. 


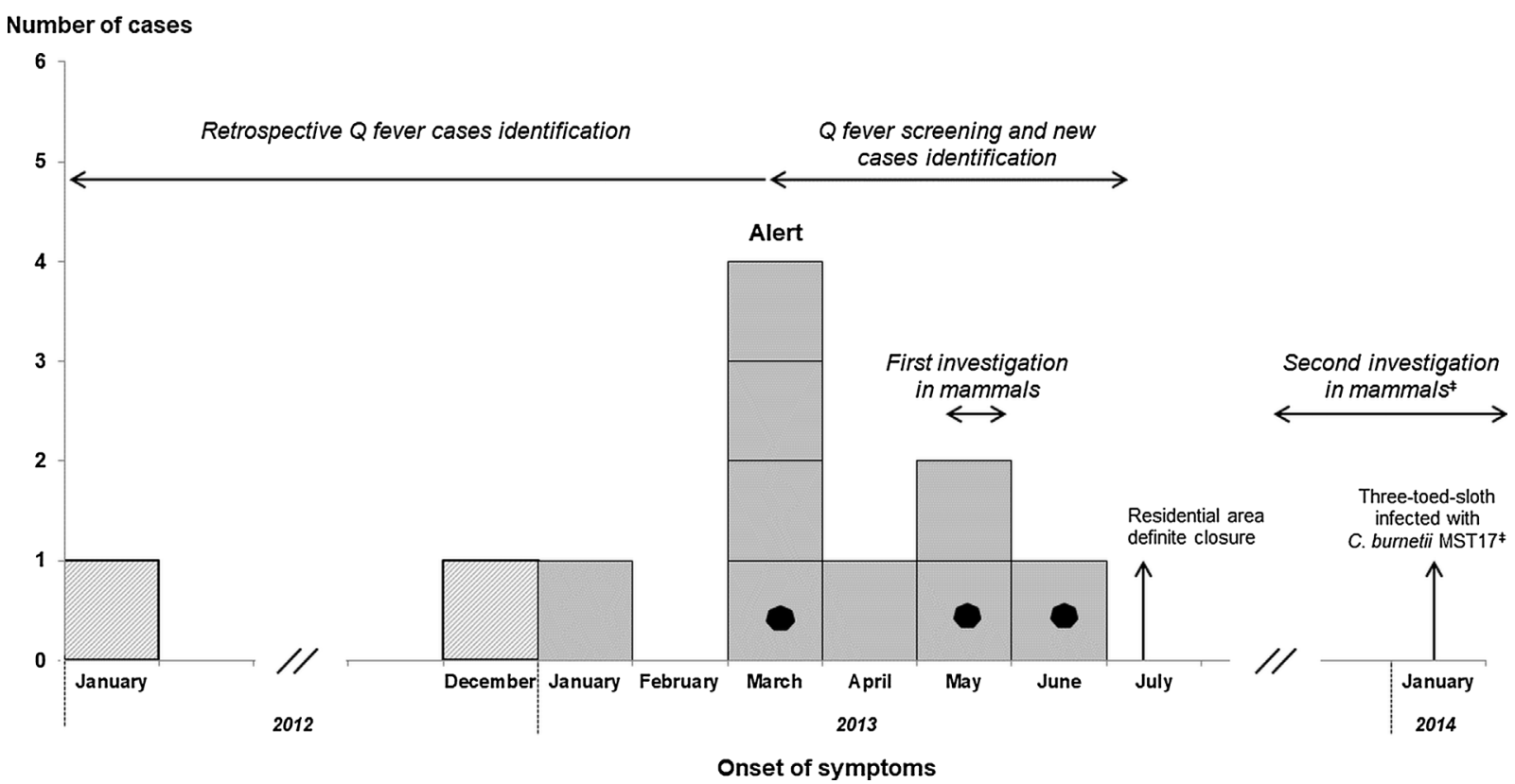

Fig. 2. Epidemic curve $(\mathrm{N}=11 \mathrm{Q}$ fever cases) and different stages of the investigation in humans and mammals.

"Results of the second investigation in mammals are presented by Davoust et al. [6]

Samples were therefore targeted on vaginal swab rather than fecal swabs during this outbreak $[14,15]$. DNA samples were purified by QIAamp DNA Blood Mini Kit and QIAamp DNA Mini Kit (Qiagen). The presence of IS1111 was tested by real time PCR and amplicons were detected on a 7300 real-time PCR System (Applied Biosystems) using primers and probes previously designed [16]. In parallel, a nested PCR was also performed to detect low concentration of $C$. burnetii using the following primers F1: TACTGGGTGTTGATATTGC, R1: CACCGCGGAT GAAACGG, F2: GTAAAGTGATCTACACGA, R2: ACGTTCAAGCGCTGT TAA on a Mastercycler Gradient (Eppendorf) using HotStar Taq DNA polymerase (Qiagen).

For the immunofluorescence test, serum samples diluted at $1 / 50$ in PBS were left for $30 \mathrm{~min}$ at $37^{\circ} \mathrm{C}$ and then washed in PBS; slides were incubated for $30 \mathrm{~min}$ at $37^{\circ} \mathrm{C}$ with the Rabbit anti-Opossum IgG Antibody (Novus biologicals) at dilution $1 / 200$ and washed in PBS; slides were incubated for $30 \mathrm{~min}$ at $37^{\circ} \mathrm{C}$ with the Anti-Rabbit IgG-FITC antibody produced in goat (Sigma) at dilution 1/160 and washed in PBS.

\subsection{Statistical analysis}

Univariate and multivariate analysis were performed using SAS $9.3^{\circ}$ software. Considering small sample size leading to large confidence intervals of odds ratio in this cohort study, we used Log-binomial model to estimate adjusted relative risks ( $\mathrm{RRa}$ ) in multivariate analysis as previously described [17].

\section{Results}

For the 54 inhabitants' population, median age was 32.5 years (interquartile range: $10-38$ years; min: 2 months - max 48 years) and the sex ratio was 1.0 (27 males and 27 females). Eleven $Q$ fever cases were confirmed, seven men and four women and only one was $<15$ years-old (Table 1). Diagnosis of acute $Q$ fever were confirmed by serology with positive IgM in nine cases (IgM phase I: median titer 800 , min: 50-max: 6400; IgM phase II: median titer 800, min: 400-max:
1600; IgG phase II: median titer 800; min 200-max 6400 - seroconverting in seven cases) (Fig. 2). In addition, two acute $\mathrm{Q}$ fever cases were also confirmed by IS1111 qPCR on lyophilized serum, respectively with $\mathrm{C}_{\mathrm{t}}$ value of 31,32 . A third case presented a IS1111 qPCR with a low $\mathrm{C}_{\mathrm{t}}$ value of 39 . These three samples were identified as $C$. burnetii MST17, the unique clone circulating in Cayenne (the third sample was positive only after a re-amplification of DNA). Blood cultures were negative. Two other cases were identified as $\mathrm{Q}$ fever past (but recent) infection (Fig. 2). They presented several months before an unexplained and prolonged (7 days) fever episode, while living in the residential area. These two patients had no previous history of $\mathrm{Q}$ fever or exposure to $C$. burnetii in France prior to their stay in French Guiana. Both presented elevated IgG titer: IgG phase $\mathrm{I}=200$ and IgG phase II $=400$ without IgM.

The eleven $\mathrm{Q}$ fever cases were symptomatic with fever $>38.5^{\circ} \mathrm{C}$ $(11 / 11)$, cough $(8 / 11)$, headache $(8 / 11)$, myalgia $(8 / 11)$, and arthralgia (4/11). Among them, four cases presented community-acquired pneumonia and three isolated fever. Considering the first case confirmed in March 2013, investigations allowed confirming retrospectively five cases (symptomatic cases without prior diagnosis) and five new acute $\mathrm{Q}$ fever cases during the three-month follow-up. The overall attack rate was 20 percent $(11 / 54)$ (Fig. 2). The epidemic lasted seven months, from December 2012 to June 2013 with a peak of four cases in March 2013. Q fever cases were identified in $50 \%$ of the residential area' homes (8/16-two dwellings were not occupied during the epidemic period) (Fig. 1). None of the cases developed persistent localized $Q$ fever after an 18-month follow-up.

In univariate analysis, $\mathrm{Q}$ fever risk factors were to be active military personnel $(\mathrm{RR}=4.5 \mathrm{CI95 \%}$ [1.4-15.2]) and some activities in the month preceding symptoms: to clean the house ( $\mathrm{RR}=8.6 \mathrm{CI} 95 \%$ [1.2-62.7]), to use high-pressure cleaner $(\mathrm{RR}=2.9 \mathrm{CI} 95 \%$ [1.1-7.9] $)$ and to have carried a three-toed sloth in arms ( $\mathrm{RR}=3.7 \mathrm{CI} 95 \%$ [1.4-9.6]) (Table 1). Log binomial multivariate models identified two independent risk factors: to clean the house (RRa $=7.5 \mathrm{CI} 95 \%$ $[1.03-55.3])$ and to carry a three-toed sloth in arms (RRa $=2.6 \mathrm{CI} 95 \%$ [1.1-5.8]). 
Table 1

Retrospective cohort study, risk factors for contracting $\mathrm{Q}$ fever, univariate and log-binomial multivariate analysis (no $=11 \mathrm{Q}$ fever cases, $\mathrm{N}=54$ subjects).

\begin{tabular}{|c|c|c|c|c|}
\hline \multirow[t]{2}{*}{ Variables } & \multicolumn{2}{|l|}{$\mathrm{Q}$ fever incidence (I) } & \multirow{2}{*}{$\frac{\text { Univariate }}{\mathrm{RR}^{\mathrm{c}}[\mathrm{CI} 95 \%]}$} & \multirow{2}{*}{$\begin{array}{l}\text { Multivariate } \\
\mathrm{RRa}^{\mathrm{d}}[\mathrm{CI} 95 \%]\end{array}$} \\
\hline & no. $/ \mathrm{n}$ exposed $\left(\mathrm{Ie}^{\mathrm{a}}\right)$ & no./non exposed $\left(\right.$ Ine $\left.^{\mathrm{b}}\right)$ & & \\
\hline \multicolumn{5}{|l|}{ Sociodemographic } \\
\hline Sex (Male $v s$ Female) & $7 / 27(25.9)$ & $4 / 27(14.8)$ & $1.8[0.6-5.3]$ & \\
\hline Age $>15$ years & $10 / 35(28.6)$ & $1 / 19(5.3)$ & $5.4[0.8-39.3]$ & \\
\hline Military $v s$ family members & $8 / 20(40.0)$ & $3 / 34(8.8)$ & $4.5[1.4-15.2]$ & - \\
\hline \multicolumn{5}{|l|}{ Activities in the past month } \\
\hline Clean the house & $10 / 29(34.5)$ & $1 / 25(4.0)$ & $8.6[1.2-62.7]$ & $7.5[1.03-55.3]$ \\
\hline Use of high-pressure cleaner & $5 / 12(41.7)$ & $6 / 42(14.3)$ & $2.9[1.1-7.9]$ & \\
\hline Tinker in the home basement & $7 / 21(33.3)$ & 4/33 (12.1) & $2.8[0.9-8.3]$ & \\
\hline Walk in the surrounding forest & $4 / 16(25.4)$ & $7 / 38(18.4)$ & $1.4[0.5-4.0]$ & \\
\hline Practice gardening & $5 / 18(27.8)$ & $6 / 36(16.7)$ & $1.7[0.6-4.7]$ & \\
\hline Use air conditioning at home & $2 / 11(18.2)$ & 9/43 (20.9) & $0.9[0.2-3.5]$ & \\
\hline \multicolumn{5}{|l|}{ Contact with animals around home } \\
\hline See three-toed sloth & $9 / 38(23.7)$ & $2 / 16(12.5)$ & $1.9[0.5-7.8]$ & \\
\hline Hold three-toed sloth in arms & $3 / 5(60.0)$ & $8 / 49(16.3)$ & $3.7[1.4-9.6]$ & $2.6[1.1-5.8]$ \\
\hline See marsupials & $1 / 6(16.7)$ & $10 / 48(20.8)$ & $0.8[0.1-5.2]$ & \\
\hline See bats & $2 / 8(25.0)$ & $9 / 46(19.6)$ & $1.3[0.3-4.9]$ & \\
\hline See others mammals & $5 / 38(18.8)$ & $6 / 16(37.5)$ & $0.6[0.3-1.2]$ & \\
\hline Clean wild animal feces & $5 / 23(21.7)$ & $6 / 31(19.4)$ & $1.1[0.4-3.2]$ & \\
\hline Cat at home & $2 / 8(25.0)$ & $9 / 46(19.6)$ & $1.3[0.3-4.9]$ & \\
\hline Dog at home & $5 / 25(20.0)$ & $6 / 29(20.7)$ & $1.0[0.3-2.8]$ & \\
\hline Tick bite & $1 / 4(25.0)$ & $10 / 50(20.0)$ & $1.3[0.2-7.5]$ & \\
\hline
\end{tabular}

Data in bold: statistically significant results.

${ }^{a}$ Ie: incidence of $\mathrm{Q}$ fever among exposed subjects.

${ }^{\mathrm{b}}$ Ine: incidence of $\mathrm{Q}$ fever among non-exposed subjects.

${ }^{\mathrm{c}} \mathrm{RR}$ : relative risk (Ie/Ine).

${ }^{\mathrm{d}}$ RRa: adjusted relative risk estimated using log-binomial multivariate analysis.

Of the 18 marsupial individuals, all PCR performed on blood, vaginal swabs and ticks were negative but $17 \%(3 / 18)$ had a positive serology, $2 D$. marsupialis and $1 P$. opossum.

\section{Discussion and conclusions}

Human Q fever cases mainly occur after inhalation of contaminated aerosols. Infectious aerosols are contaminated with $C$. burnetii from the waste (feces, urine, birth products) of infected animals. In this outbreak, human contamination mainly occurs through inhalation of infectious aerosols of dusts as suggested by high relative risk observed with house cleaning activities and the use of high pressure cleaner.

We identify close contact with three-toed sloth as a risk factor for $\mathrm{Q}$ fever. The same strain $C$. burnetii genotype 17 has been laboratoryconfirmed in this mammal and in human cases. These results support the implication of three-toed-sloth in this outbreak. The capture rate was low (18 marsupials captured for a total effort of 138 traps during 6 nights) but comparable to other surveys conducted with similar trapping methods [18]. None of the other animals captured during the epidemic period was found infected with $C$. burnetii MST17 despite confirmed positive ticks on three-toed-sloth [6]. Considering C. burnetii was finally detected in feces of a three-toed-sloth during the second investigation in mammals, the choice of restricting the study to vaginal swabs was a limit of the study [6]. We recommend that future studies consider this outcome and systematically include feces testing. In all $17 \%$ of marsupials had positive antibodies confirming wildlife exposure and perhaps a more complex sylvatic transmission cycle among wild mammals, as recently observed with rodents in Brazil [19]. The outbreak occurred in a close area surrounded by rainforest where wildlife is abundant. This is in favor of close dissemination of bacteria in the environment by wild mammals. Although one three-toed sloth is identified as a zoonotic risk, there are likely to be other factors and animals that could have played a role in this environment and this outbreak.

Ten other cases were secondary confirmed around the first confirmed case. All the cases presented symptoms but half were initially undiagnosed fever. The absence of asymptomatic forms compared to the usually $60 \%$ described for $\mathrm{Q}$ fever, could be related to the unique and hypervirulent $C$. burnetii genotype 17 circulating in Cayenne $[5,11,20,21]$. These results emphasize the importance of grouped $Q$ fever cases investigation and systematic repeated $C$. burnetii serology in case of fever without diagnosis in French Guiana [22].

Considering the high attack rate and the absence of validated prevention measures, the residential area has finally been closed in July and the occupants resettled.

\section{References}

[1] C. Eldin, A. Mahamat, M. Demar, P. Abboud, F. Djossou, D. Raoult, Q fever in French Guiana, Am. J. Trop. Med. Hyg. 91 (4) (2014) 771-776.

[2] F. Pfaff, A. Francois, D. Hommel, I. Jeanne, J. Margery, G. Guillot, Y. CouratteArnaude, A. Hulin, A. Talarmin, Q fever in French Guiana: new trends, Emerg. Infect. Dis. 4 (1) (1998) 131-132.

[3] J. Gardon, J.M. Heraud, S. Laventure, A. Ladam, P. Capot, E. Fouquet, J. Favre, S. Weber, D. Hommel, A. Hulin, Y. Couratte, A. Talarmin, Suburban transmission of Q fever in French Guiana: evidence of a wild reservoir, J. Infect. Dis. 184 (3) (2001) 278-284.

[4] L. Epelboin, C. Chesnais, C. Boulle, A.S. Drogoul, D. Raoult, F. Djossou, A. Mahamat, $\mathrm{Q}$ fever pneumonia in French Guiana: prevalence, risk factors, and prognostic score, Clin. Infect. Dis. 55 (1) (2012) 67-74.

[5] A. Mahamat, S. Edouard, M. Demar, P. Abboud, J.Y. Patrice, B. La Scola, A. Okandze, F. Djossou, D. Raoult, Unique clone of Coxiella burnetii causing severe Q fever, French Guiana, Emerg. Infect. Dis. 19 (7) (2013) 1102-1104.

[6] B. Davoust, J.L. Marie, V. Pommier de Santi, J.M. Berenger, S. Edouard, D. Raoult, Three-toed sloth as putative reservoir of Coxiella burnetii, cayenne, French Guiana, Emerg. Infect. Dis. 20 (10) (2014) 1760-1761.

[7] C. Eldin, A. Mahamat, F. Djossou, D. Raoult, Rainfall and sloth births in may, q Fever in july, cayenne, French Guiana, Am. J. Trop. Med. Hyg. 92 (5) (2015) 979-981.

[8] A. Tran, J. Gardon, S. Weber, L. Polidori, Mapping disease incidence in suburban areas using remotely sensed data, Am. J. Epidemiol. 156 (7) (2002) 662-668.

[9] S. Edouard, A. Mahamat, M. Demar, P. Abboud, F. Djossou, D. Raoult, Comparison between emerging $\mathrm{Q}$ fever in French Guiana and endemic Q fever in Marseille, France, Am. J. Trop. Med. Hyg. 90 (5) (2014) 915-919.

[10] S. Edouard, D. Raoult, Lyophilization to improve the sensitivity of qPCR for bacterial DNA detection in serum: the Q fever paradigm, J. Med. Microbiol. 65 (6) (2016) 426-427.

[11] F. D'Amato, C. Eldin, K. Georgiades, S. Edouard, J. Delerce, N. Labas, D. Raoult, Loss of TSS1 in hypervirulent Coxiella burnetii 175, the causative agent of Q fever 
in French Guiana, Comp. Immunol. Microbiol. Infect. Dis. 41 (2015) 35-41.

[12] M. Million, G. Walter, F. Thuny, G. Habib, D. Raoult, Evolution from acute Q fever to endocarditis is associated with underlying valvulopathy and age and can be prevented by prolonged antibiotic treatment, Clin. Infect. Dis. 57 (6) (2013) 836-844.

[13] N.R. Parker, J.H. Barralet, A.M. Bell, Q fever, Lancet 367 (9511) (2006) 679-688.

[14] R. de Cremoux, E. Rousset, A. Touratier, G. Audusseau, P. Nicollet, D. Ribaud, V. David, M. Le Pape, Coxiella burnetii vaginal shedding and antibody responses in dairy goat herds in a context of clinical Q fever outbreaks, FEMS Immunol. Med. Microbiol. 64 (1) (2012) 120-122.

[15] T.J. O'Neill, J.M. Sargeant, Z. Poljak, A systematic review and meta-analysis of phase I inactivated vaccines to reduce shedding of Coxiella burnetii from sheep and goats from routes of public health importance, Zoonoses Public Health 61 (8) (2014) 519-533.

[16] P.M. Schneeberger, M.H. Hermans, E.J. van Hannen, J.J. Schellekens, A.C. Leenders, P.C. Wever, Real-time PCR with serum samples is indispensable for early diagnosis of acute Q fever, Clin. Vaccine Immunol. 17 (2) (2010) 286-290.

[17] L.A. McNutt, C. Wu, X. Xue, J.P. Hafner, Estimating the relative risk in cohort studies and clinical trials of common outcomes, Am. J. Epidemiol. 157 (10) (2003) 940-943.

[18] B. de Thoisy, V. Lacoste, A. Germain, J. Munoz-Jordan, C. Colon, J.F. Mauffrey, M. Delaval, F. Catzeflis, M. Kazanji, S. Matheus, P. Dussart, J. Morvan, A.A. Setien, $\mathrm{X}$. Deparis, A. Lavergne, Dengue infection in neotropical forest mammals, Vector Borne Zoonotic Dis. 9 (2) (2009) 157-170.

[19] T. Rozental, M.S. Ferreira, A. Guterres, M.A. Mares-Guia, B.R. Teixeira, J. Goncalves, C.R. Bonvicino, P.S. D'Andrea, E.R. de Lemos, Zoonotic pathogens in Atlantic Forest wild rodents in Brazil: Bartonella and Coxiella infections, Acta Trop. 168 (2017) 64-73.

[20] M. Million, D. Raoult, Recent advances in the study of Q fever epidemiology, diagnosis and management, J. Infect. 71 (Suppl. 1) (2015) S2-9.

[21] D. Raoult, T. Marrie, J. Mege, Natural history and pathophysiology of Q fever, Lancet Infect. Dis. 5 (4) (2005) 219-226.

[22] V. Pommier de Santi, J.L. Marié, S. Briolant, A. Mahamat, F. Djossou, L. Epelboin, T. Lamour, B. de Thoisy, D. Raoult, S. Edouard, B. Davoust, Q fever in French Guiana: a specific epidemiological context [In French], Bull. Acad. Vet. France 169 (1) (2016) 148-154. 